\title{
Stiff, porous scaffolds from magnetized ceramic particles aligned by magnetic freeze casting
}

\author{
Michael B. Frank ${ }^{1 *}$, Steven E. Naleway ${ }^{2}$, Tsuk Haroush ${ }^{3}$, Chin-Hung Liu ${ }^{1}$, Sze Hei Siư ${ }^{3}$, Jerry Ng ${ }^{3}$, \\ Ivan Torres ${ }^{3}$, Ali Ismail ${ }^{3}$, Keyur Karandikar ${ }^{1}$, Michael M. Porter ${ }^{4}$, Olivia A. Graeve ${ }^{1,3}$, Joanna McKittrick ${ }^{1,3}$ \\ ${ }^{1}$ Materials Science and Engineering Program \\ University of California, San Diego, 9500 Gilman Drive, La Jolla, CA 92093, USA \\ ${ }^{2}$ Department of Mechanical Engineering \\ University of Utah, 1495 E 100 S, Salt Lake City, UT 84112, USA \\ ${ }^{3}$ Department of Mechanical and Aerospace Engineering \\ University of California, San Diego, 9500 Gilman Drive, La Jolla, CA 92093, USA \\ ${ }^{4}$ Department of Mechanical Engineering \\ Clemson University, Clemson, SC, 29634, USA \\ *Corresponding Author: mbfrank@ucsd.edu; tel: 1-858-229-6146; fax: 1-858-534-5698
}

\begin{abstract}
Bone consists of a hard mineral phase and a compliant biopolymer phase resulting in a composite material that is both lightweight and strong. Osteoporosis that degrades spongy bone preferentially over time leads to bone brittleness in the elderly. A porous ceramic material that can mimic spongy bone for a one-time implant provides a potential solution for the future needs of an aging population. Scaffolds made by magnetic freeze casting resemble the aligned porosity of spongy bone. A magnetic field applied throughout freezing induces particle chaining and alignment of lamellae structures between growing ice crystals. After freeze drying to extract the ice and sintering to strengthen the scaffold, cubes from the scaffold center are mechanically compressed along longitudinal (z-axis, ice growth direction) and transverse ( $y$-axis, magnetic field direction) axes. The best alignment of lamellar walls in the scaffold center occurs when applying magnetic freeze casting with the largest particles $(350 \mathrm{~nm})$ at an intermediate magnetic field strength $(75 \mathrm{mT})$, which also agrees with stiffness enhancement results in both $z$ and $y$-axes. Magnetic moments of different sized magnetized alumina particles help determine the ideal magnetic field strength needed to induce alignment in the scaffold center rather than just at the poles.
\end{abstract}

KEYWORDS: freeze casting, ferrofluid, magnetic alignment, ceramic scaffold,mechanical properties 


\section{INTRODUCTION}

Gravity and electromagnetism are natural forces responsible for celestial body assembly in the universe. On a much smaller scale, Earth's magnetic field plays some role in "biological body" assembly, or how living organisms orient themselves with respect to their surrounding environment [1]]. Biogenic magnetite $\left(\mathrm{Fe}_{3} \mathrm{O}_{4}\right)$ has been found in sharks [2] ], pigeons []ㅡ, honeybees [4]], humans [ㄷ], and most notably in magnetotactic bacteria that align parallel to the earth's magnetic field direction in search of microaerophilic regions of low oxygen concentration []]. These bacteria have single domain $\mathrm{Fe}_{3} \mathrm{O}_{4}$ crystals packaged within organelle magnetosomes that form a chain along the long axis of the bacteria. This magnetic sensing capability imparted by magnetosome alignment within magnetotactic bacteria provides an interesting avenue for bioinspired applications using anisotropically aligned materials that resemble naturally ordered structures.

Strong magnetic fields $(\approx 9-18 \mathrm{~T})$ have been used along with a slip casting process to finely control and texture anisotropic ceramic particlesto improve their physical, chemical and mechanical properties [7-15]. Particles in a slurry with weak anisotropic magnetic susceptibility can rotate within a strong magnetic field to an angle that minimizes the system energy. Macroscopic alignment occurs when the magnetic energy on rotation exceeds the thermal energy for the slurry particles. The degree of particle orientation depends on several processing factors in addition to the strong magnetic field, such as heating temperature, particle size and suspension viscosity [10]. Recently, magnetic slip casting has been used at much lower magnetic field strength $(<40 \mathrm{mT})$ to manipulate surface magnetized alumina $\left(\mathrm{Al}_{2} \mathrm{O}_{3}\right)$ platelets [16]. Fine control over these magnetized materials has led to reinforced composites [1720], self-shaping composites [21], tunable fluorescence emission [22], and additive manufacturing processes such as 3D magnetic printing $[\underline{23}, \underline{24}]$.

Mimicking the complex microstructures of natural materials provides a new challenge for further exploration.A common design theme froma widely studied natural material, bone, is the hierarchical organization of nanomaterials (grains, platelets or fibers) that when combined in a controlled manner,form a high strength and high toughness composite [25]. Bone is a multifunctional composite that must be strong to support the body, tough to absorb impact forces, lightweight to enable movement, and porous to replenish nutrients [26, 27]. Cortical bone provides a dense outer sheath while the interior trabecular bone enables marrow production and cell growth within the large interconnected pores of the spongy bone interior [27]. Pore alignment in load bearing regions is an important design feature along with prevention of pore expansion due to osteoporosis [28]. Fabrication 
of aligned porous structures that resemble trabecular bone necessitates methods that can provide dual levels of control over structural features with disparate length scales and along multiple directions.

Freeze casting is a physical process that uses an aqueous slurry consisting of a particulate solid phase (e.g., ceramic particles) and a freezing agent (e.g., water) [29-33]. Bulk macrostructures can be modulated via ice templated crystal growth that separates particles into lamellar structures aligned along the freezing direction (z-axis). Following a freeze drying step to remove the ice crystals, the porous scaffold consisting of lamellar walls interconnected by particlebridges is sintered to strengthen the overall structure. The quantity and dimension of the pores and the overall architecture can be modified by adjusting the solid loading [ $\underline{34}, \underline{35}]$, changing the liquid freezing agent [ㅎ6-38], and introducing additives [39-42]. Although the scaffolds are typically strong in the ice growth direction, the transverse properties are generally poor. Non-invasive methods for strengthening scaffolds along the transverse direction ( $y$-axis) normal to the freezing direction are promising next steps.

Various freeze casting techniques have been developed for scaffold pore alignment [43-46], however, Porter, et al.[47-49] were the first to apply magnetic fields during the freeze casting process. Various applied magnetic field orientations on slurry mixtures of ceramic particles and $\approx 9 \mathrm{wt} . \% \mathrm{Fe}_{3} \mathrm{O}_{4}$ particles $(\approx 50 \mathrm{~nm})$ mechanically enhanced scaffold properties normal to the ice growth axis. Most notably, atitania $\left(\mathrm{TiO}_{2}\right)$ and $\mathrm{Fe}_{3} \mathrm{O}_{4}$ slurry mixture showedweak interactions between both components when subjected to a transverse magnetic field $(\approx 120 \mathrm{mT})$ that served to align lamellar walls and strengthen the scaffold structure under compression along the magnetic field axis [47]]. $\mathrm{TiO}_{2}$ is a paramagnetic material with a weak positive magnetization and susceptibility that varies only at very low temperature $(<100 \mathrm{~K})$ or at a very high applied magnetic field. In another study, zirconia $\left(\mathrm{ZrO}_{2}\right)$ and $\mathrm{Fe}_{3} \mathrm{O}_{4}$ slurry mixtureswere subjected to a rotating magnetic field $(\approx 120 \mathrm{mT})$ that produced a banded helical structure with enhanced torsional properties [48]. Recently, a transverse magnetic field ( $\approx 90 \mathrm{mT})$ applied to $\mathrm{ZrO}_{2}$ and $\mathrm{Fe}_{3} \mathrm{O}_{4}$ slurry mixture formed aligned mineral bridges with enhanced mechanical

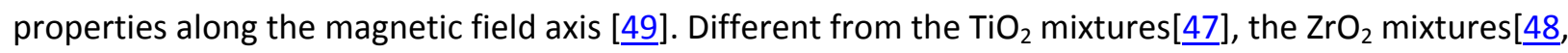
49] did not show substantial interparticle interactions between the $\mathrm{ZrO}_{2}$ and $\mathrm{Fe}_{3} \mathrm{O}_{4}$ phases, which led to distinct separation of the phases, and subsequently, the helical or bridge-like features.

Below a critical diameter ( $\approx 120 \mathrm{~nm}$ ), $\mathrm{Fe}_{3} \mathrm{O}_{4}$ exists in a single domain state whereby all spins align uniformly in an applied magnetic field direction[50]. Superparamagnetism occurs in smaller $\mathrm{Fe}_{3} \mathrm{O}_{4}$ particles $(<15-20 \mathrm{~nm})$ as a super moment that can easily flip in response to a changing magnetic field.This behavior is due to the particle thermal energy ( $k_{B} T$, Boltzmann's constant · temperature) exceeding the magnetic anisotropy energy barrier $\left(K_{\text {eff }} V\right.$, anisotropy constant - particle volume) that 
typically fixes magnetic moments in place along a particular direction. Superparamagnetic $\mathrm{Fe}_{3} \mathrm{O}_{4}$ is therefore quite different from larger particles made up of ferromagnetic (elemental iron, nickel, cobalt) or ferrimagnetic (oxides of iron, nickel, cobalt) materials that behave like permanent magnets regardless of an applied magnetic field.

Superparamagnetic $\mathrm{Fe}_{3} \mathrm{O}_{4}$ used in concert with non-magnetic materials has low magnetic field applications. Dynabeads ${ }^{\circledR}$ (Thermo Fisher Scientific, Waltham, MA) comprise a core of superparamagnetic $\mathrm{Fe}_{3} \mathrm{O}_{4}$ surrounded by a polystyrene shell. These composites respond even at low magnetic field strength and are often functionalized for magnetically controlled separation applications [51]. Recently, researchers surface magnetized ceramic particles with ferrofluid[17], which consists of a stable suspension of superparamagnetic $\mathrm{Fe}_{3} \mathrm{O}_{4}$ particles $(\approx 10 \mathrm{~nm})$ coated with a stabilizing dispersing agent (surfactant) in a liquid carrier. The surfactant charge has a dual purpose for preventing $\mathrm{Fe}_{3} \mathrm{O}_{4}$ particle agglomeration in the ferrofluid and facilitating electrostatic adsorption of $\mathrm{Fe}_{3} \mathrm{O}_{4}$ to the ceramic particle surface. Ceramic particles in water have a point-of-zero charge (PZC), which is the pH when the surface becomes electrostatically neutral [드], and water molecules hydroxylate the surface to become protonated or deprotonated according to the Gouy-Chapman theory [53]. For example, $\mathrm{Al}_{2} \mathrm{O}_{3}(\mathrm{PZC} \approx 9)$ [54] in water $\left(\mathrm{PZC} \approx 7\right.$ ) becomes protonated and superparamagnetic $\mathrm{Fe}_{3} \mathrm{O}_{4}$ particles, coated with anionic surfactant, electrostatically adhere to magnetize the surface of the larger, non-magnetic material.

Equations that describe chain formation of single domain $\mathrm{Fe}_{3} \mathrm{O}_{4}(\approx 50 \mathrm{~nm})$ in magnetosomes of magnetotactic bacteria [ $\underline{55}$ ]can be used to predict how isolated superparamagnetic $\mathrm{Fe}_{3} \mathrm{O}_{4}$ particles [드] and Dynabeads ${ }^{\circledR}[\underline{57}, \underline{58}]$ in water respond to a magnetic field gradient. For non-magnetic materials surface magnetized with sparsely attached superparamagnetic $\mathrm{Fe}_{3} \mathrm{O}_{4}$, particle-particle magnetic interaction is described by the ratio between particle interaction energy $(U)$ and thermal energy $\left(k_{B} T\right)$ to obtain a unitless magnetic coupling parameter $(\Gamma)$, according to the following equations:

$$
\begin{gathered}
U=\frac{\mu_{0} m^{2}}{4 \pi d^{3}}\left[1-3 \cos ^{2} \theta\right] \\
\Gamma=\frac{U}{k_{B} T}=\frac{\mu_{0} m^{2}}{2 \pi d^{3} k_{B} T}
\end{gathered}
$$

where $\mu_{0}$ is the magnetic permeability of free space $\left(4 \pi \times 10^{-7} \mathrm{H} / \mathrm{m}\right), m$ is the particle magnetic moment dipole, $d$ is the center-center interparticle distance (equal to one particle diameter for particles touching in a chain) and $\theta$ s the angle between the external magnetic field direction and the line that connects between the centers of two particles.

The equation for $\Gamma$ stipulates that a minimum energy configuration exists at $\theta=0^{\circ}$. The inset inFigure 1 shows how the formation of highly anisotropic, aligned assemblies in solution occurs due to 
magnetic dipole-dipole interaction energy between particles at strongly attractive regions where $\theta=0^{\circ}$ (vertical, indicated in red), instead of at strongly repulsive regions where $\theta>54.7^{\circ}$ (horizontal, indicated in green)[57]. Particle-particle interactions for colloidal stability are described by classical DLVO theory [59] that includes attractive van der Waals forces and repulsive electrostatic forces. Generalization of DLVO theory to include magnetic interaction leads to a theoretical overall free energy profile of interaction between two electrostatically stable particles $[\underline{57}, \underline{60}, \underline{61}]$. The electrostatic repulsion responsible for particle stabilization creates an energy barrier between a deep primary minimum (due to van der Waals attraction) and a shallow secondary minimum (due to magnetic interaction energy), as shown in Figure 1. The depth of the secondary minimum depends on the value of $\Gamma$. Particles captured in the secondary minimum aggregate to form chains in the presence of a magnetic field gradient due to a sufficiently large magnetic interaction energy. The secondary minimum disappears when the magnetic field is removedand the particles redisperse within the liquid medium without addition of energy.

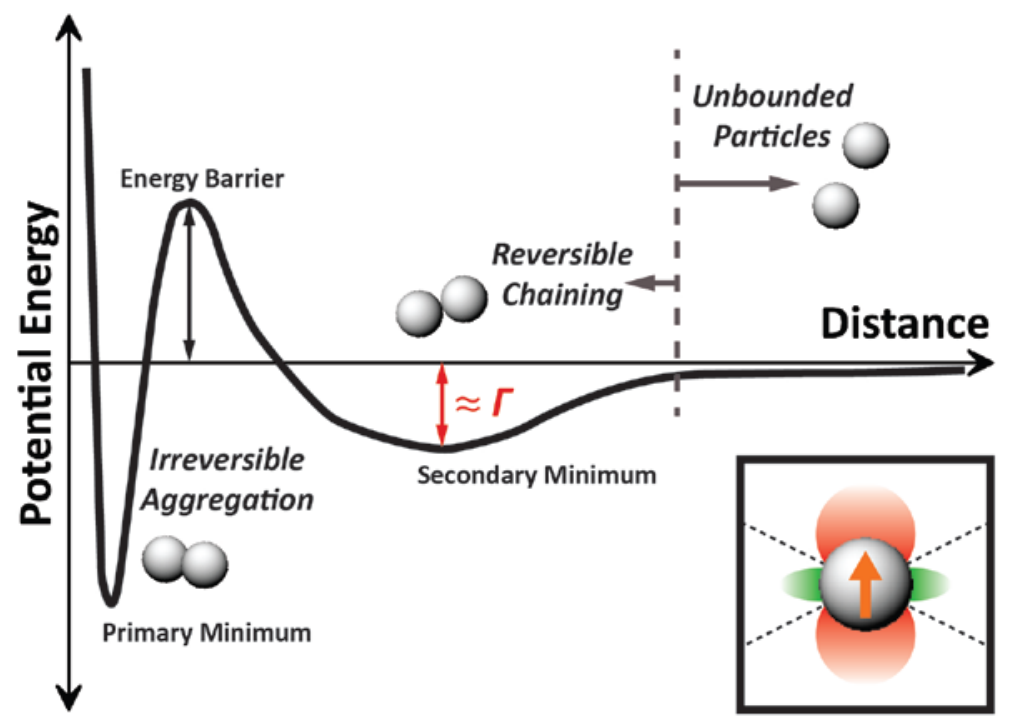

Figure 1. Free energy profile diagram of interaction between electrostatically stabilized spherical particles that have been surface magnetized with superparamagnetic particles and subjected to a strong magnetic field. Assumptions applied from a generalized DLVO theory include a deep primary minimum (van der Waals attraction), an energy barrier (electrostatic repulsion) and a secondary minimum (magnetic interaction, vertical, indicated in red) where chain formation occurs according to the magnetic coupling parameter $(\Gamma)$ value. Repulsive regions (horizontal, indicated in green) exist on the sides due to the particle dipole (up arrow, indicated in orange) oriented in the magnetic field direction.

This reversible chaining of superparamagnetic $\mathrm{Fe}_{3} \mathrm{O}_{4}$ in combination with non-magnetic materials has diverse applications besides its use in polymer coated Dynabeads ${ }^{\circledR}$ for magnetic separation. A value of $\Gamma \gg>1$ corresponds to a system dominated by magnetic interactions with particle chain formation, whereas $\Gamma<<1$ results in no particle chaining due to a preponderance of thermal agitation. However, 
chain formation is not easily predictable in experimental systems with values close to $\Gamma \approx 1$ for superparamagnetic particles alone [ㄷ6, $\underline{57}]$ or when surrounded by non-magnetic material. For example, previous work on superparamagnetic $\mathrm{Fe}_{3} \mathrm{O}_{4}$ surrounded by a silica shell $(\Gamma=3.5)$ did not form particle chains, although this was suggested to have been due to leftover capping agent that could have had a significant impact on the observed result [2] . Magnetic freeze casting with surface magnetized ceramic particles provides an alternative avenue for experimental validation of particle chain formation from measurement of $\Gamma$ and mechanical characterization of sintered scaffolds.

This work investigates a new method for making multi-axis strengthened porous structures that resemble trabecular bone by magnetic freeze casting with surface magnetized $\mathrm{Al}_{2} \mathrm{O}_{3}$ particles. The magnetic field strength needed to align lamellar walls for stiffness enhancement in the transverse direction is explored. The magnetization method applied here provides better control over smaller superparamagnetic $\mathrm{Fe}_{3} \mathrm{O}_{4}$ electrostatically adsorbed to the larger $\mathrm{Al}_{2} \mathrm{O}_{3}$ particle surface. Any structural materials that respond either weakly (e.g., $\mathrm{TiO}_{2}$ ) or not at all (e.g., $\mathrm{ZrO}_{2}, \mathrm{Al}_{2} \mathrm{O}_{3}$, hydroxyapatite) to a magnetic field can be surface magnetized, thus control over macro and microstructures by magnetic freeze casting can provide afeasible pathway towards construction of dynamic material systems that sense, interact with and even adapt to the surrounding environment [63].

\section{MATERIALS AND METHODS}

\subsection{Particle Surface Magnetization}

Three different $\alpha-\mathrm{Al}_{2} \mathrm{O}_{3}$ particles (BMA15, $150 \mathrm{~nm}$; SM8, $350 \mathrm{~nm}$; CR6, $500 \mathrm{~nm}$; particle size estimated by supplier Baikowski, Malakoff, TX, USA)were surface magnetized, as shown in Figure 2. For each particle size, $2.5 \mathrm{~g} \mathrm{Al}_{2} \mathrm{O}_{3}$ was stirredin $75 \mathrm{~mL}$ distilled water, while $100 \mu \mathrm{L}$ of anionic ferrofluid (EMG705, Ferrotec, Bedford, NH, USA) was diluted in $5 \mathrm{~mL}$ distilled water in a separate container and dropwise added to the stirring $\mathrm{Al}_{2} \mathrm{O}_{3}$ solution. After stirring for 12 hours, white colored $\mathrm{Al}_{2} \mathrm{O}_{3}$ particles changed to a light brown color and the surrounding solution became clear. Residual anionic surfactant was rinsed off from magnetized particles with distilled water and vacuum filtration. The magnetized $\mathrm{Al}_{2} \mathrm{O}_{3}$ was then dried for 12 hours at $100^{\circ} \mathrm{Cbeforeuse} \mathrm{in} \mathrm{magnetic} \mathrm{freeze} \mathrm{casting} \mathrm{slurries.}$ 


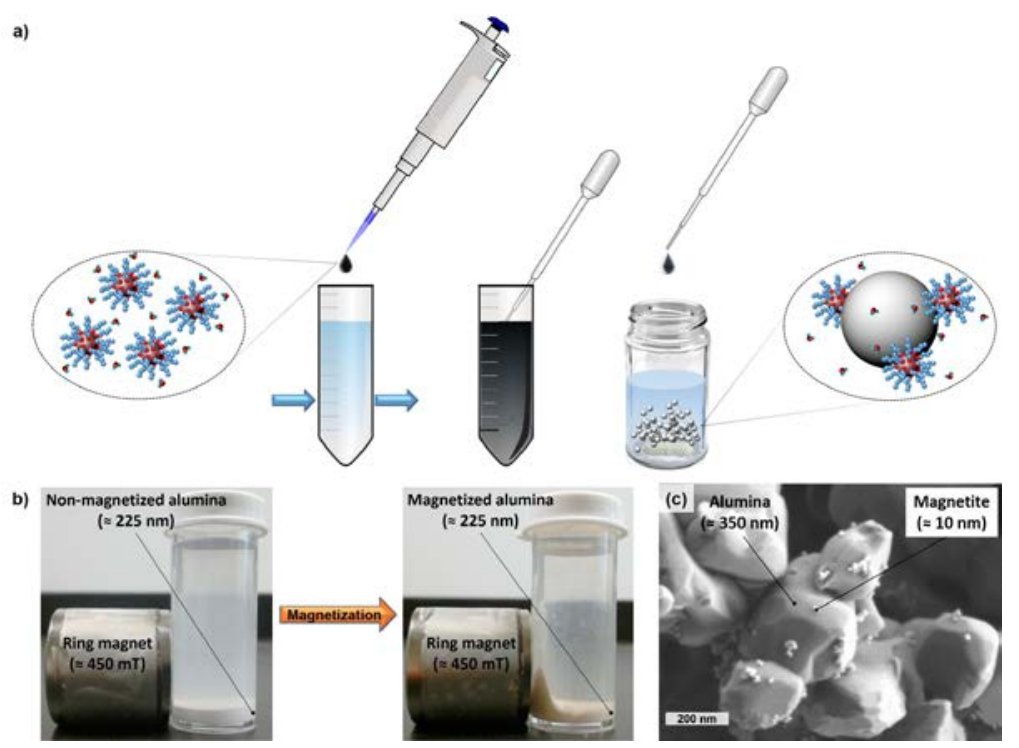

Figure 2. Preparation of magnetized alumina particles. (a)Ferrofluid consisting of magnetite $(\approx 10 \mathrm{~nm})$ nanoparticles coated with an anionic surfactant was diluted and dropwise added to a stirring alumina slurry. (b) Non-magnetic alumina particles (left) became magnetized (right) after stirring for 12 hours. (c) Scanning electron micrograph of magnetized alumina particles $(\approx 350 \mathrm{~nm})$ with magnetite on the surface.

\subsection{Magnetized Slurry Preparation}

Magnetized $\mathrm{Al}_{2} \mathrm{O}_{3}$ particle slurries (10 vol.\%) were prepared (by weight $\mathrm{Al}_{2} \mathrm{O}_{3}$ ) with polymer binders 1 wt.\% polyvinyl alcohol (PVA, 100,000 g/mol molecular weight (MW), Alfa Aesar, Ward Hill, MA, USA), 1 wt.\% polyethylene glycol (PEG, 10,000 g/mol MW, Alfa Aesar, Ward Hill, MA, USA) and 1 wt.\% anionic dispersant (Darvan 811, R. T. Vanderbilt Company, Inc., Norwalk, CT, USA). $\mathrm{Al}_{2} \mathrm{O}_{3}$ grinding media was addedto the slurry and the mixture was ball milled for 24 hours. After milling, particle sizes, measured at least twenty times by the dynamic light scattering (DLS) technique (MicrotracNanotrac Wave II, Montgomeryville, PA), provided a number distribution of the mean particle diameter[64-66].

\subsection{Magnetic Freeze Casting}

A vise grip (Panavise, Reno, NV) with $\approx 420 \mathrm{mT}$ bar magnets (N52 grade, K\&J Magnetics, Inc. Pipersville, PA, USA) attached to either end allowed for a static magnetic field apparatus that was adjustable. A handheld Gauss meter measured the magnetic field strength at the gap, located at the midpoint between the magnets.An exponential curve fit from the data points was acquired at successively increasing $5 \mathrm{~mm}$ gap intervals, yielding an equation for conversion of gap distance to magnetic field strength. The Gauss meter measurements closely resembled calculated values for two disc magnets attached to an iron yoke, as shown in Figure 3. Freeze casting with magnetized 
$\mathrm{Al}_{2} \mathrm{O}_{3}$ subjected to no magnetic field versus a static transverse magnetic field $(\approx 25,75,150 \mathrm{mT})$ was accomplished in a polyvinyl chloride (PVC) mold. A groove was filed along the inside wallof the mold andaligned perpendicular to the magnetic field axis to provide a visual indicator where the magnetic field was applied on the sintered samples.

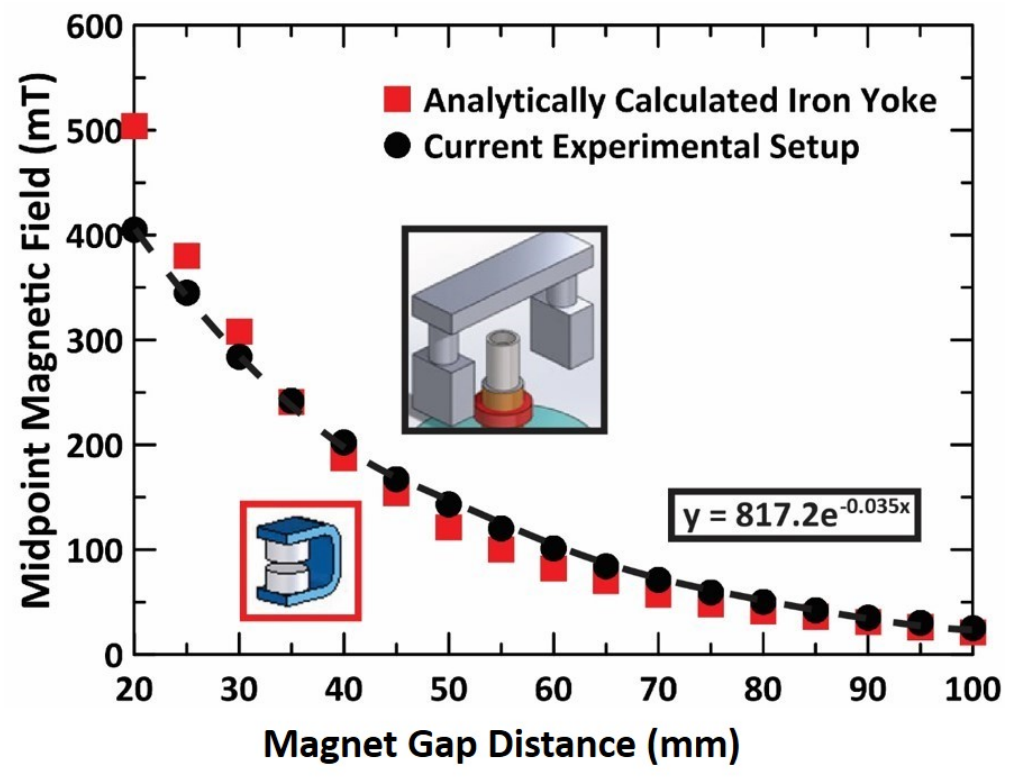

Figure 3. Gap magnetic field strength determination via theoretical calculation and measurement. Plotted red squares indicatecalculated magnetic field strength at increasing gap distancesfor two disc magnets attached to an iron yoke. Plotted black circles and trend line indicate measured magnetic field strength at increasing gap distances with a Gauss meter at the center point between bar magnets.

Each surface magnetized $\mathrm{Al}_{2} \mathrm{O}_{3}$ slurry was degassed under low vacuum for 15 minutes beforepouring $5 \mathrm{~mL}$ into the PVC freeze cast mold. The static magnetic field apparatus was situatedand centered on the PVC mold, as shown in Figure 4a. Directional freezing occurred from the bottom upward using a custom built freeze casting device, as previously described [47]. Frozen solid samples were lyophilized with a bench-top freeze dryer (Labconco, Kansas City, MO, USA) at $-50^{\circ} \mathrm{C}$ and $3.5 \times 10^{-6} \mathrm{~Pa}$ for 48 hours. Ice crystals sublimed leaving behind fragile 'green body' scaffolds composed of particles held together by the polymer binders. Samples were sintered in an open air furnace for 3 hours at $1500^{\circ} \mathrm{C}$ with heating and cooling rates of $2^{\circ} \mathrm{C} / \mathrm{min}$, following a procedure that provided reproducible results with uniform porosity [4]]. 
a)

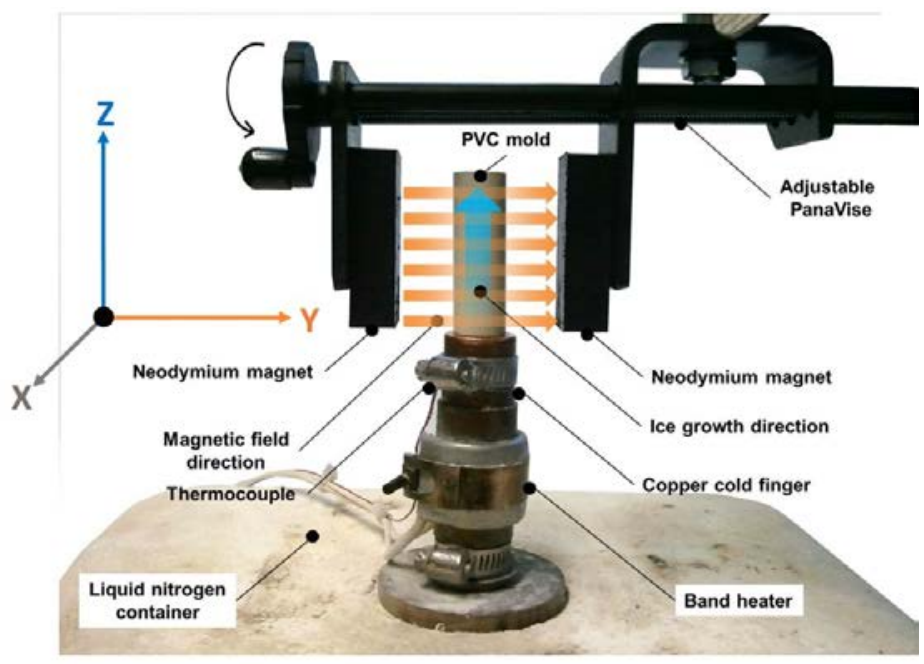

b)

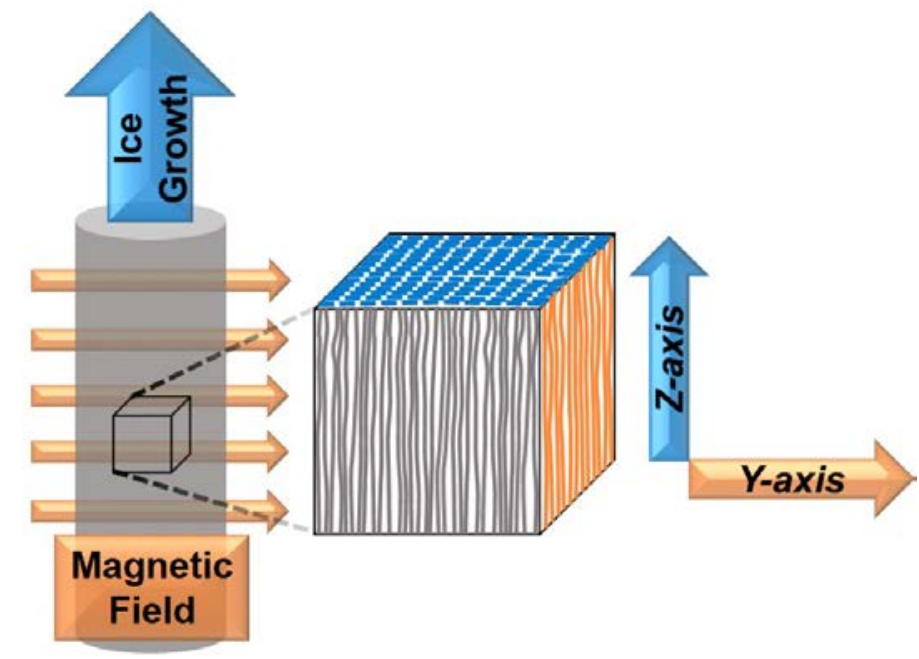

Figure 4. Magnetic freeze casting setup and sintered scaffold cube compression diagram. (a) Ice crystals grow along the z-axis while a static magnetic field is applied along the $y$-axis. (b) Mechanical properties are compared via cubes from the center of the sintered scaffold compressed in the ice growth direction ( $z$-axis, blue cube face) and the magnetic field direction ( $y$-axis, orange cube face).

\subsection{Materials Characterization}

Magnetized $\mathrm{Al}_{2} \mathrm{O}_{3}$ particles $(\approx 15-30 \mathrm{mg}$ ) were characterized with a vibrating sample magnetometer (VSM, VersaLab, Quantum Design International, San Diego, CA, USA) with momentmeasured in response to a sweeping magnetic field (0-3000 Oe). Mass magnetization ( $M$, $\left.\mathrm{Am}^{2} / \mathrm{kg}\right)$ and particle magnetic moment $\left(m, \mathrm{Am}^{2}\right)$ was calculated from magnetometer measurements coupled with particle volume $(v)$ measured by DLS, according to the following equations:

$$
\begin{gathered}
M=\text { moment } / \text { sample weight } \\
m=v \times M
\end{gathered}
$$


Sintered scaffolds sectioned at midpoint height were mounted to a stage and coated with colloidal graphite along the bottom and side walls. Iridium was sputter coated (EMITech K575X, Quorum Technologies Ltd., West Sussex, UK) for $15 \mathrm{~s}$ at $85 \mathrm{~mA}$ onto the top. Scanning electron microscopy (SEM) micrographsat $10 \mathrm{kV}$ (spot size $3 \mathrm{~nm}$ ) froma Philips XL30 field emission environmental scanning electron microscope (FEI-XL30, FEI Company, Hillsboro, OR)was used to characterize scaffold pore dimensions.Image analysis with ImageJ software (National Institutes of Health, Bethesda, MD, USA) maintained acontrast threshold at a consistent value in all micrographs. An ellipse fit to each measured pore provideddimensions for the major axis $(a)$ and minor axis (b). For each scaffold, 40 individual pores were measured to obtain pore area $\left(A_{p}=\pi a b / 4\right)$ and lamellar wall thickness $(t)$, which was how other scaffolds were analyzed in previous work $[\underline{41}, \underline{42}]$.

\subsection{Mechanical Characterization}

Compression testing of sintered $\mathrm{Al}_{2} \mathrm{O}_{3}$ scaffolds was performed on a 3342 Instron materials testing machine (Instron, Norwood, MA) with a $500 \mathrm{~N}$ static load cell at a crosshead velocity of 0.005 $\mathrm{mm} / \mathrm{s}$. Two samples ( $\approx 5 \mathrm{~mm}^{3}$ cubes) cut from each scaffold center (Figure $4 \mathrm{~b}$ )were compressed, one in the ice growth direction ( $z$-axis) and the otherin the magnetic field direction ( $y$-axis). Ultimate compressive strength and Young's modulus were determined from the maximum stress and linear slope of the stress-strain curves, respectively.

\section{RESULTS AND DISCUSSION}

\subsection{Magnetic Response of Magnetized Alumina Particles}

$\mathrm{Al}_{2} \mathrm{O}_{3}$ particle sizes were estimated by the supplier to be $150 \mathrm{~nm}$ (BMA15), $300 \mathrm{~nm}$ (SM8) and $500 \mathrm{~nm}$ (CR6), however, average particle sizes measured by DLS after ball milling were actually $195 \mathrm{~nm}$, $225 \mathrm{~nm}$ and $350 \mathrm{~nm}$, respectively, as shown in Figure 5. Equal weights of different sized $\mathrm{Al}_{2} \mathrm{O}_{3}$ particles were magnetized with equalvolumes of ferrofluid to ensure equal amounts of surface adsorbedFe $\mathrm{O}_{4}$. VSM measurements converted to particle magnetic moment, $m$, (Eqns. 3, 4)showed a correlation with particle size (Figure 6). Since $\Gamma$ is proportional to $\mathrm{m}^{2}$ (Eqn. 2), larger particles were more likely to overcome thermal agitation dominance and Brownian motion compared with smaller particles [ㄷ]]. 


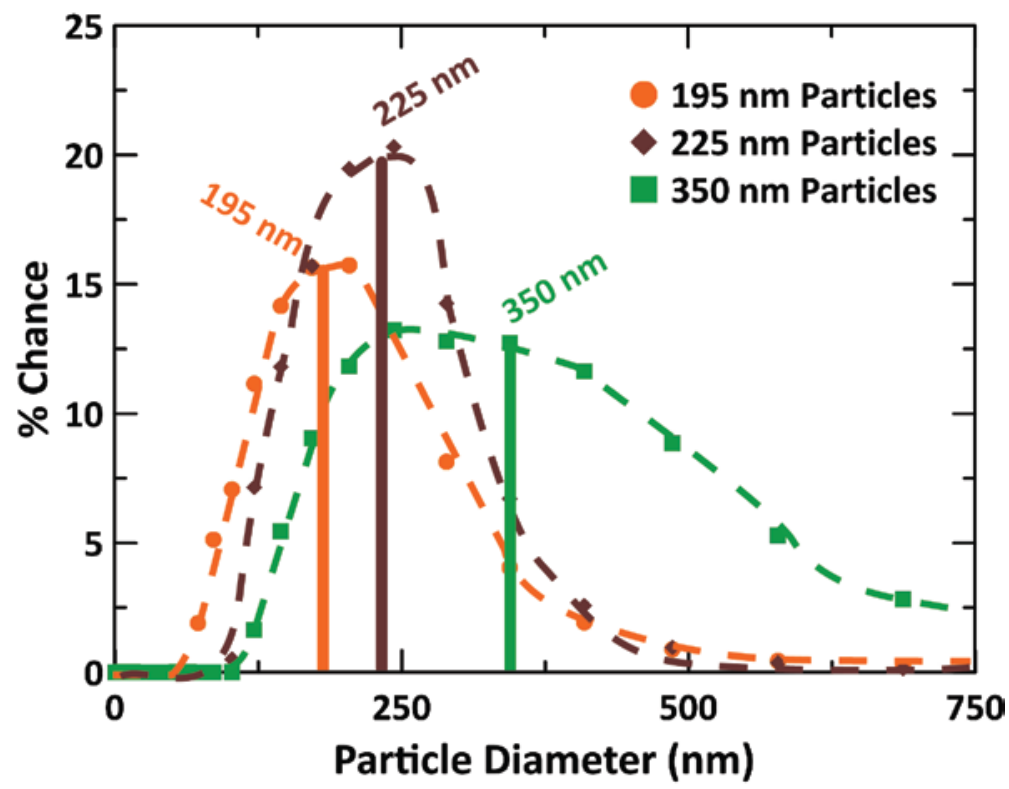

Figure 5. Dynamic light scattering measurement of alumina particle sizes. Each particle type was segmented into a mean number distribution that consisted of particle percentage at different particle size bins and plotted for comparison. The product of each particle percentage with corresponding bin size was summed to determine the reported mean for each particle type.

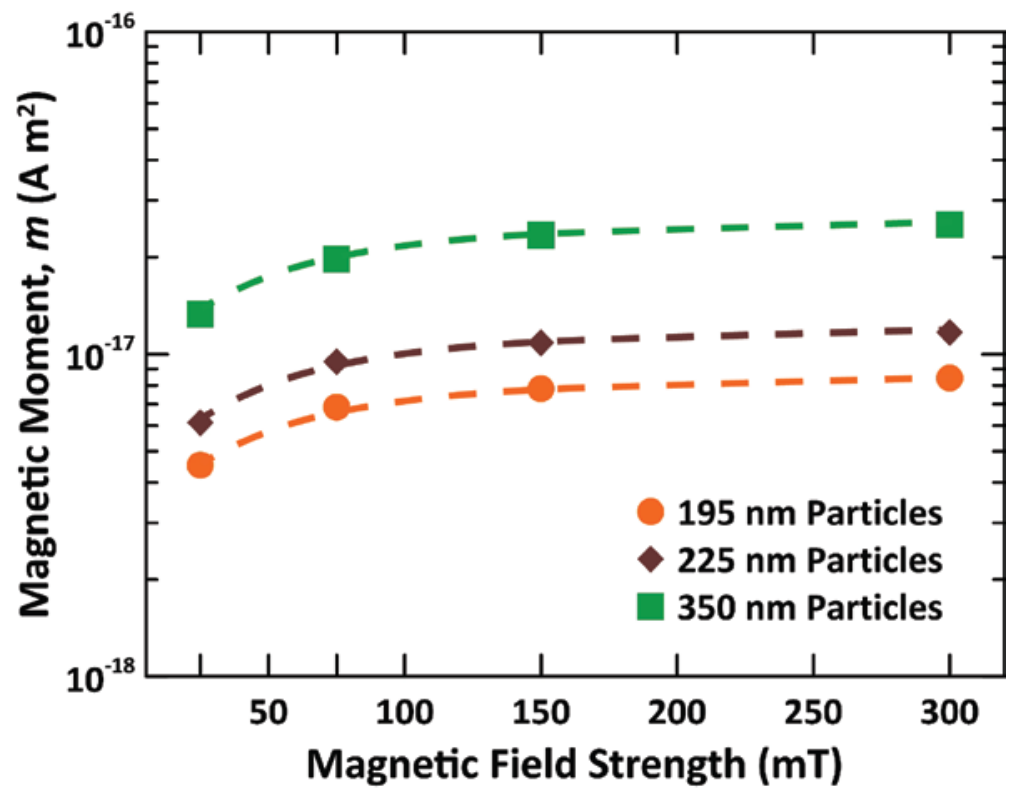

Figure 6. Comparison of particle magnetic moment, $m$, determined from magnetometer measurements for different sized magnetized alumina particles. The value mis squared in the numerator of Eqn. 2 and is the product of the measured magnetic moment, density and spherical particle volume divided by the sample weight. Larger magnetized alumina particles have greater values for $m$ than smaller particles.

DLS measured average $\mathrm{Al}_{2} \mathrm{O}_{3}$ particle size, $d$, andVSMmeasured moment, $m$, were combined in Eqn. 2 to obtain $\Gamma$ as a function of applied magnetic field strength (left side, Figure 7a-c).For each average 
particle size, $\Gamma$ fell below the threshold $(\Gamma>1)$ predicted for particle chaining when magnetic interaction energy exceeds thermal agitation. Since average particle size poorly represents the actual size disparityevidentin a mean number distribution for each $\mathrm{Al}_{2} \mathrm{O}_{3}$ particle type (Figure 5), $\Gamma$ was recalculated to determinepercent for each particle type above the threshold $(\Gamma>1)$ at a magnetic field strength of 75 $\mathrm{mT}$ (right side, Figure 7a-c). The 195, 225 and $350 \mathrm{~nm}$ particles had 8\%, 11\% and 20\% of each type above the threshold $(\Gamma>1)$ at $75 \mathrm{mT}$, respectively, while $16 \%, 25 \%$ and $33 \%$ were above the same threshold at $150 \mathrm{mT}$, respectively.
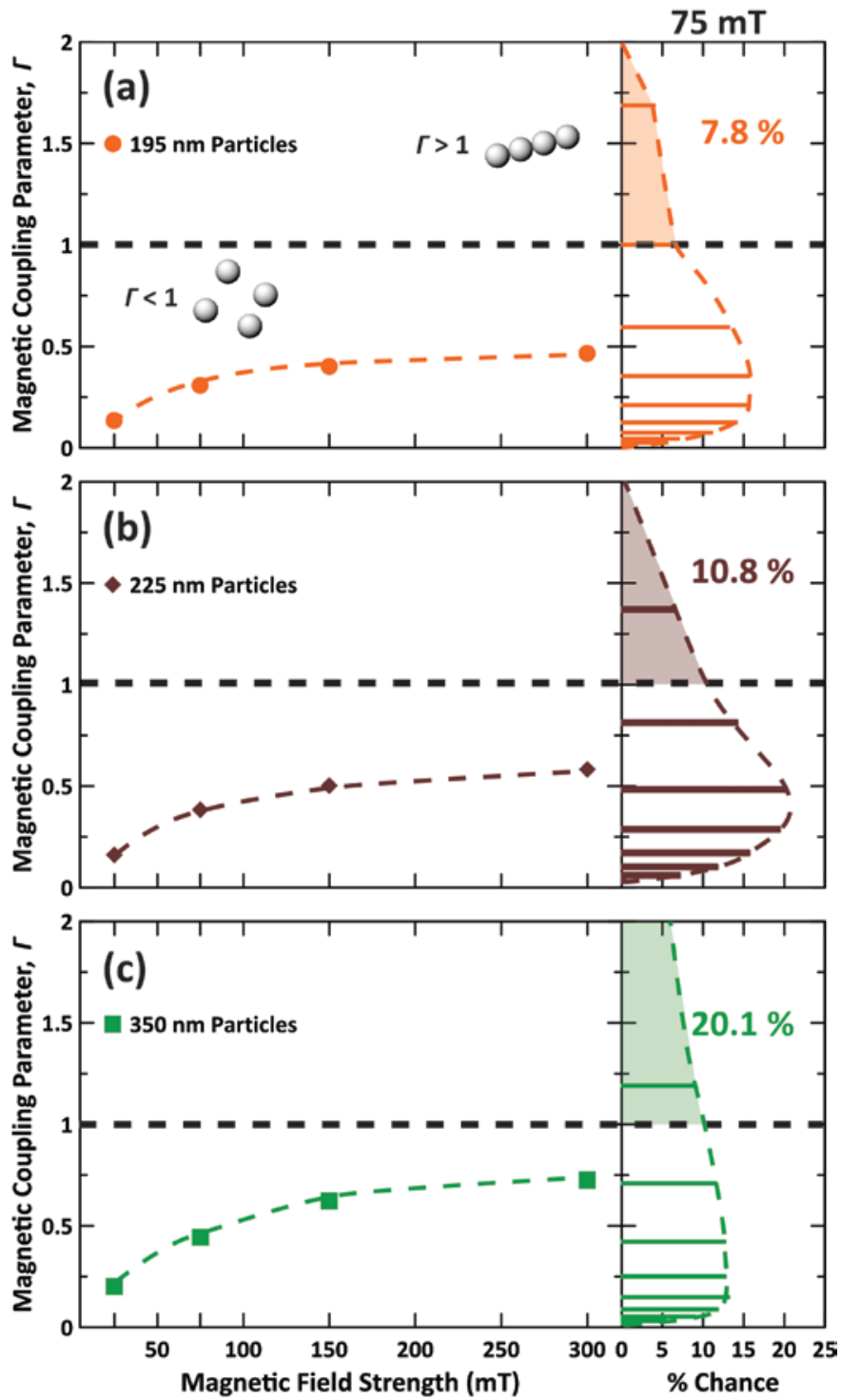

Figure 7. Comparison of the calculated magnetic coupling parameter $(\Gamma)$ values and mean number distribution of particle sizes for different sized alumina particles. Values above $\Gamma \approx 1$ were not evident at any magnetic field strength for (a) $195 \mathrm{~nm}$, (b) $225 \mathrm{~nm}$ or (c) $350 \mathrm{~nm}$ particles. A higher percentage of larger particles within the DLS measured mean number distribution for $350 \mathrm{~nm}$ particles had values above $\Gamma \approx 1$. 


\subsection{Lamellar Wall Alignment}

During the time before freezing started, magnetized particles subjected to an applied magnetic fieldlikely underwentparticle chaining in a manner similar to previously reported 1D chain formation of $\mathrm{Fe}_{3} \mathrm{O}_{4}$ nanoclusters at room temperature in aqueous solution [67]. A slurry temperature of $298 \mathrm{~K}$ was used in Eqn. 2for the calculated $\Gamma$ values (Figure 7), which underestimated $\Gamma$ by $\approx 10 \%$ because $T$ was $\leq$ $273 \mathrm{~K}$ just before freezing actually occurred.Chaining betweenthe percent of larger slurry particlesabove the threshold $(\Gamma>1)$ likely contributed to guiding the formation of lamellar walls alignedbetween growing ice crystals. Mineral bridges made up of particles trapped within the growing ice frontcould then connect between adjacent lamellae in a similar fashion as in normal freeze casting.

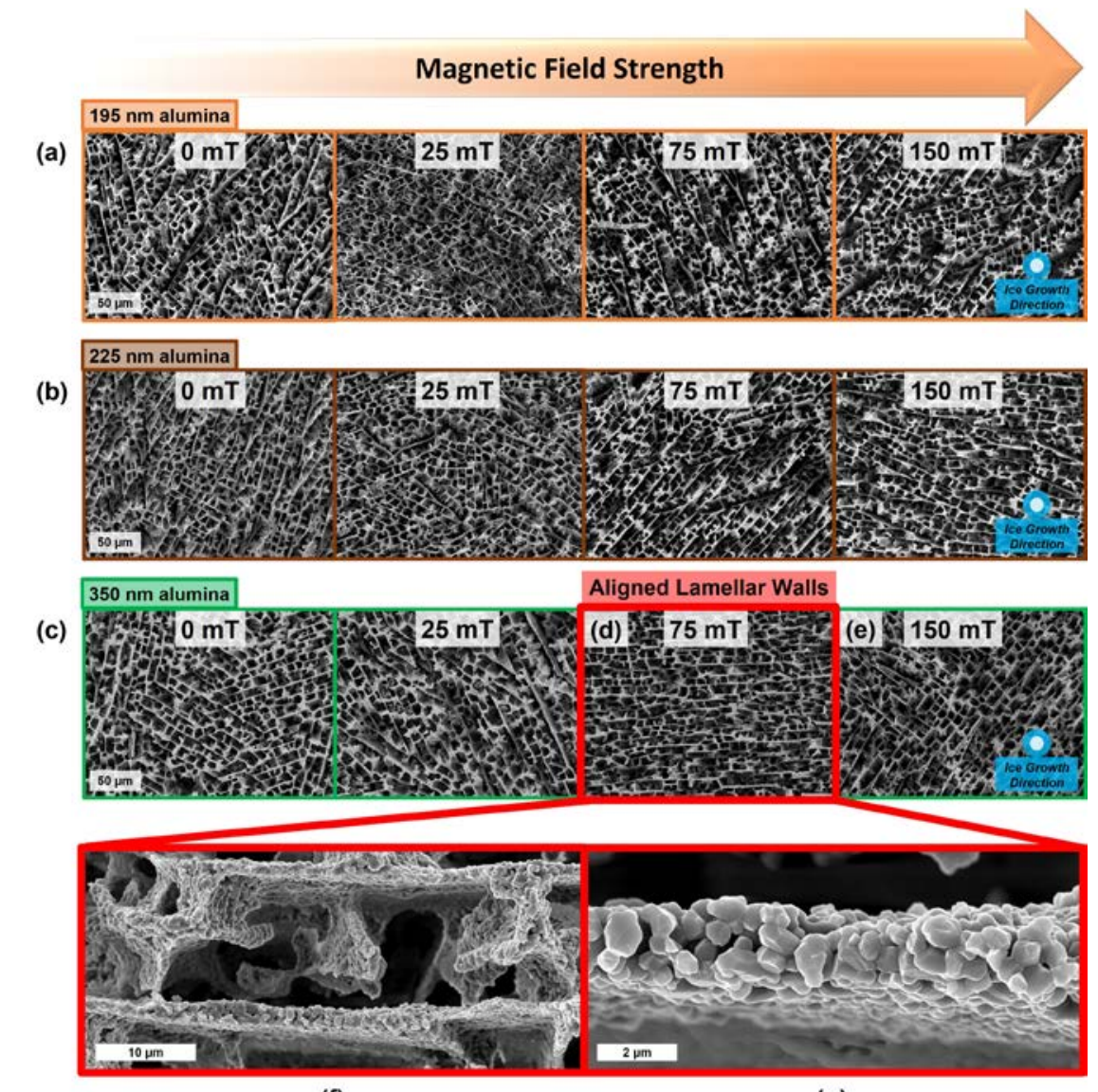

(f)

(g)

Figure 8. Scanning electron micrographs of scaffold center regions for different sized magnetized alumina particles after magnetic freeze casting at 0, 25, 75 and $150 \mathrm{mT}$.(a) $195 \mathrm{~nm}$ alumina particles did not exhibit lamellar wall alignment at any of the applied magnetic fields, while (b) $225 \mathrm{~nm}$ alumina particles had limited alignment at $150 \mathrm{mT}$.(c) $350 \mathrm{~nm}$ alumina particles had lamellar wall alignment that was most evident at (d) $75 \mathrm{mT}$, however, at (e) $150 \mathrm{mT}$ there was disordered alignment likely due to flux field effects. (f) Closer examination of the scaffold microstructures shows mineral bridge formation and(g) particles sintered together within lamellar walls aligned along the magnetic field axis. 
In Figure 8, SEM micrographs from the center of the scaffolds show transverse cross-sections perpendicular to the ice growth direction(Figure 8a-c). As expected for each particle size, no lamellar wall alignment occurred during freeze casting when there was no applied magnetic field. All of the magnetic field conditions for $195 \mathrm{~nm}$ scaffolds indicated no alignment of lamellar walls along the magnetic field axis (Figure 8a). Some regions of lamellar wall alignment were evident for $225 \mathrm{~nm}$ scaffolds at $150 \mathrm{mT}$, but none at lower strength magnetic fields (Figure 8b). For $350 \mathrm{~nm}$ scaffolds (Figure 8c), more lamellar wall alignment was evident at $75 \mathrm{mT}$ (Figure 8d) than at $150 \mathrm{mT}$ (Figure 8e).Image analysis of stitched together SEM micrographs $(6 \mathrm{~mm} \times 2.7 \mathrm{~mm})$ from the center of $350 \mathrm{~nm}$ scaffolds indicated $\approx 20 \%$ lamellar wall alignment at 75 mTand $\approx 12 \%$ alignment at $150 \mathrm{mT}$ (results not shown). Interestingly, calculation of particle chaining percentage from DLS measured particle size (d) andVSMmeasured moment $(m)$ above the threshold $(\Gamma>1)$, for $350 \mathrm{~nm}$ slurries at $75 \mathrm{mT}$, was actually borne out by lamellar wall alignment in the scaffold center, although not at $150 \mathrm{mT}$. This result indicates that a sufficient, but not excessive, amount of applied magnetic field strength is necessary to align lamellar walls in the scaffold center. High magnification SEM micrographs of $350 \mathrm{~nm}$ scaffolds show lamellar wall alignment and mineral bridge formationat $75 \mathrm{mT}$ (Figure 8f,g) along the (horizontal) magnetic field axis.

Different sizedAl ${ }_{2} \mathrm{O}_{3}$ particles in this study produced scaffolds withsimilar porosity $(\approx 80-85 \%$, Table 1$)$ and lamellar wall thickness $(2.3-3 \mu \mathrm{m}$, Table 1$)$ as previous freeze casting work with $\mathrm{ZrO}_{2}[\underline{35}]$ and $\mathrm{TiO}_{2}[41]$ that had the same processing conditions. However, the pore area for the $\mathrm{Al}_{2} \mathrm{O}_{3}$ scaffolds (35-45 $\mu \mathrm{m}^{2}$,Table 1) was more than $20 x$ and 5xsmaller thanfor $\mathrm{ZrO}_{2}$ [35] and $\mathrm{TiO}_{2}[\underline{41}$ ] scaffolds, respectively, despite $\mathrm{Al}_{2} \mathrm{O}_{3}$ particles having similar sizes as $\mathrm{ZrO}_{2}$ and $\mathrm{TiO}_{2}$ particles. Molecular dynamic simulations indicate material properties (e.g.,surface morphology, hydrophobicity, lattice mismatch)[68] and particle surface modification with adsorbedmolecules can significantly increase or decrease ice nucleation rate[69], which can explain thisdiscrepancy. For the case of freeze casting at a slower cooling ramp $\left(5^{\circ} \mathrm{C} / \mathrm{min}\right)$ with a wide range of $\mathrm{Al}_{2} \mathrm{O}_{3}$ sizes $(0.2-3.4 \mu \mathrm{m})$, Deville, et al. [70] speculated that smaller particles with higher surface area had more ice nucleation sites that led to scaffolds with larger pore area and lamellar wall thickness. For this study, a much narrower size range of $\mathrm{Al}_{2} \mathrm{O}_{3}$ particleslikelymitigated any large difference betweennumber of nucleation sites, although pore area and lamellar wall thickness slightly increased for larger magnetized $\mathrm{Al}_{2} \mathrm{O}_{3}$ particles (Table 1). Altered ice nucleation rates in other freeze casting systemsusing different solidification rates, materials, particle sizes and unmodified surfaces can furthercomplicate comparison of measured scaffold properties. Additional experimental 
work on heterogeneous ice nucleation is certainlyneeded to correlate empirical results with fundamental understanding of physiochemical processes frommolecular dynamics simulations [68].

Table 1. Porosity, pore area and lamellar wall thickness of alumina particle scaffolds freeze cast at various static magnetic fields $(0,75,150 \mathrm{mT})$. Sample size for each condition: $N=6$. All data reported are mean \pm standard error (standard deviation $/ \sqrt{ } \mathrm{N}$ ).

\begin{tabular}{|l|c|c|c|c|}
\hline & $\begin{array}{c}\text { Magnetic } \\
\text { field } \\
\text { strength } \\
(\mathbf{m T})\end{array}$ & $\mathbf{1 9 5} \mathbf{n m}$ particles & $\mathbf{2 2 5} \mathbf{~ n m}$ particles & $\mathbf{3 5 0} \mathbf{~ n m}$ particles \\
\hline Porosity (\%) & 0 & $83.74 \pm 0.15$ & $83.35 \pm 0.17$ & $82.60 \pm 0.19$ \\
& 75 & $84.77 \pm 0.29$ & $83.44 \pm 0.18$ & $82.33 \pm 0.18$ \\
& 150 & $85.29 \pm 0.11$ & $81.60 \pm 0.33$ & $81.83 \pm 0.58$ \\
\hline Pore area & 0 & $37.28 \pm 2.57$ & $41.20 \pm 2.56$ & $43.33 \pm 2.92$ \\
& 75 & $37.82 \pm 2.38$ & $38.12 \pm 2.17$ & $47.29 \pm 3.50$ \\
$\left(\boldsymbol{\mu m ^ { 2 } )}\right.$ & 150 & $34.64 \pm 2.21$ & $41.97 \pm 2.69$ & $42.54 \pm 2.53$ \\
\hline Lamellar wall & 0 & $2.32 \pm 0.05$ & $2.53 \pm 0.06$ & $2.85 \pm 0.07$ \\
thickness & 75 & $2.31 \pm 0.07$ & $2.58 \pm 0.07$ & $2.91 \pm 0.08$ \\
$(\boldsymbol{\mu m})$ & 150 & $2.34 \pm 0.09$ & $2.56 \pm 0.08$ & $3.04 \pm 0.08$ \\
\hline
\end{tabular}

Application of a low magnetic field to align magnetized $\mathrm{Al}_{2} \mathrm{O}_{3}$ particle chains within lamellar walls was primarily responsible for strengthening the scaffold along the transverse magnetic field axis.

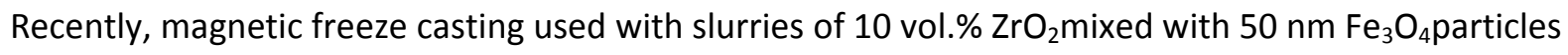
showed mineral bridge alignment and thickness increased as $\mathrm{Fe}_{3} \mathrm{O}_{4}$ content and transverse magnetic field strength increased [49]. In those slurry mixtures, larger $\mathrm{Fe}_{3} \mathrm{O}_{4}$ particles with ferromagnetic properties $(\Gamma \gg>1)$ led to particle chaining of $\mathrm{Fe}_{3} \mathrm{O}_{4}$ concentrated within aligned and thickened mineral bridges along the transverse magnetic field axis. In the present study, slight thickening of the lamellar walls occurred at varying magnetic field strength for $350 \mathrm{~nm}$ particles only (Table 1), resulting in mostly uniform microstructures compared with those presented in previous work.

\subsection{Mechanical Properties}

The porosity for scaffolds freeze cast from a slurry of 10 vol. $\% \mathrm{Al}_{2} \mathrm{O}_{3}$ was consistent across all samples ( $\approx 80-85 \%$ ), so direct comparison of mechanical properties could be correlated between particle sizes. At no applied magnetic field, pore area and lamellar wall thicknessincreased with particle size (Table 1).Figure 9a shows a representative $y$-axis stress-strain curve for the $350 \mathrm{~nm}$ scaffolds prepared with and without an applied magnetic field. The large uneven plateau region on the plot is typical of porous materials, where individual walls are fracturing over a large strain range. It is clear that the Young's modulus $(E)$ and ultimate compressive strength (UCS) are larger with the application of a 
magnetic field, corroborating the results of Porter, et al.[47] who found the same effect in $\mathrm{TiO}_{2} \mathrm{scaffolds}$ Figure 9b,c summarizesE and UCS in the $y$-axis (magnetic field direction) and $z$-axis (ice growth direction) as a function of particle size and magnetic field strength. In Figure 9b, $E$ and UCS in the $y$-axis ranged between $\approx 30-90 \mathrm{MPa}$ and $\approx 1.2-2.8 \mathrm{MPa}$, respectively. In general, both $E$ and UCS increased with increasing particle size, which is attributable to scaffolds with larger particles having thicker lamellar walls. For $225 \mathrm{~nm}$ scaffolds, $E$ increased by $\approx 50 \%$ at $150 \mathrm{mT}$ compared to ones prepared at $0 \mathrm{mT}$ (Figure 9b), while $E$ was not enhanced at any magnetic field strength for $195 \mathrm{~nm}$ scaffolds. The $350 \mathrm{~nm}$ scaffolds prepared at $75 \mathrm{mT}$ had the highest $E$ increase by $\approx 100 \%$ compared to ones prepared at $0 \mathrm{mT}$ (Figure $9 \mathrm{~b}$ ), which correlated well with enhanced lamellar wall alignment observed in SEM micrographs. During processing at $150 \mathrm{mT}$, it is likely that the magnetic flux lines were not parallel throughout the sample, but displayed some curvature, as found in finite element models for the flux lines[49]. The lower $E$ value at $150 \mathrm{mT}$ is attributable to the curvature of the magnetic flux in the scaffold center, which caused misalignment of the lamellar walls. These results demonstrate that particle sizes $<350 \mathrm{~nm}$ show no or limited effect on $y$-axis properties when having a magnetic field applied during solidification.
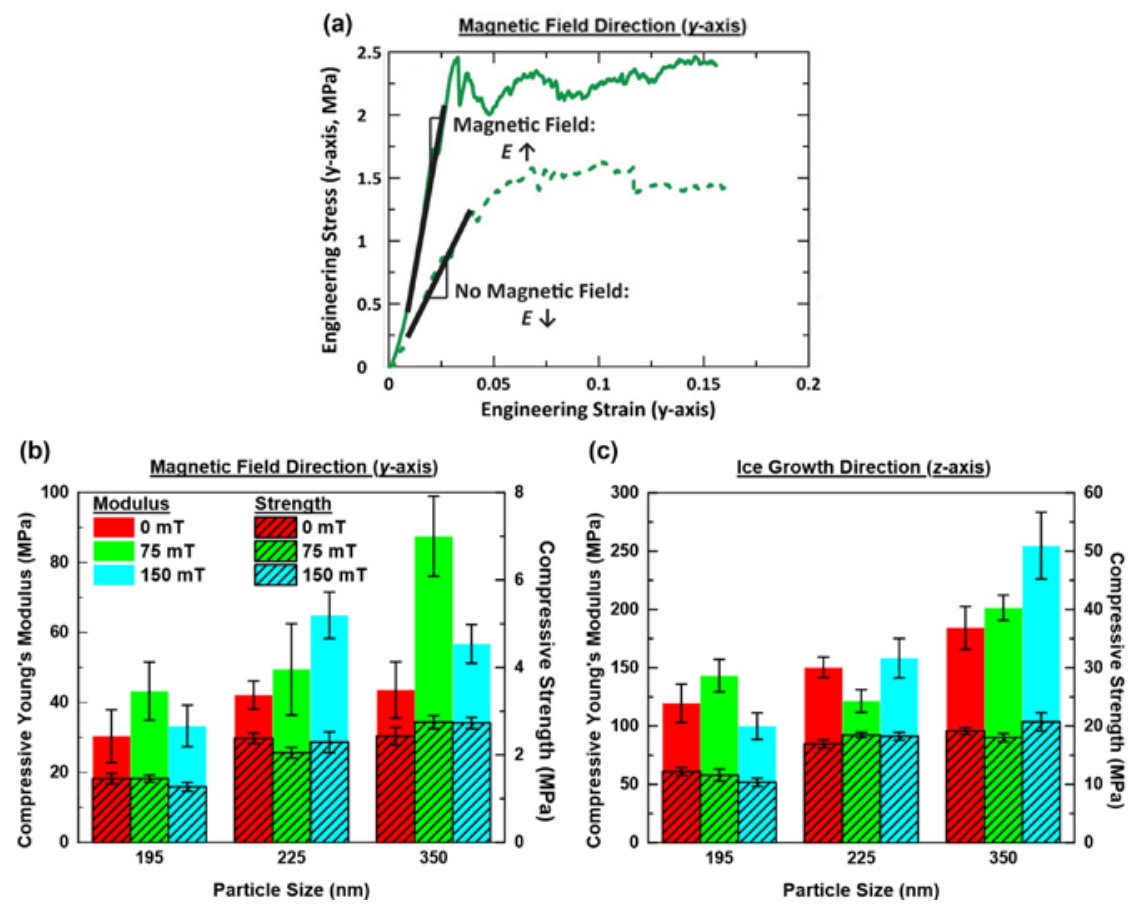

Figure 9. Comparison of compressive mechanical properties with stress-strain curve, modulus and strength values forporous scaffolds of magnetized alumina particles prepared by magnetic freeze casting. (a) A representative stress-strain curve for $350 \mathrm{~nm}$ particles made with no magnetic field (dotted line) and static magnetic field of $75 \mathrm{mT}$ (solid line). Compressive Young's modulus and ultimate strength as a function of particle size and magnetic field strength in the(b)magnetic field ( $y$-axis) and (c)ice growth direction (z-axis). Data points are the mean of $\mathrm{N}=6$ measurements with error bars representing \pm standard error (standard deviation $/ \sqrt{ } \mathrm{N}$ ). 
Figure 9cshows that $E$ and UCS in the $z$-axis ranged between $\approx 100-260 \mathrm{MPa}$ and $\approx 10-21 \mathrm{MPa}$, respectively. Both $E$ and UCS values were much greater than in the magnetic field directionbecausemore lamellar wall alignment occurred in the ice growth direction. In general, both $E$ and UCS increased with particle size in the $z$-axis, again due to the increase in lamellar wall thickness (Table 1). For $350 \mathrm{~nm}$ scaffolds, more so than for $195 \mathrm{~nm}$ or $225 \mathrm{~nm}$ scaffolds, increased magnetic field strength produced ordered regions of lamellar walls oriented parallel to each other in "grains" along axes transverse to the freezing direction. Generally, scaffold compression along the z-axis causes crack formation and growth to occur due to local buckling of lamellar walls. However, for $350 \mathrm{~nm}$ scaffolds subjected to increased magnetic field strength, the compressive load was distributed more evenly by ordered regions of aligned walls ("grains") with mineral bridges between parallel lamellae that prevented Euler buckling by hindering crack propagation $[\underline{39}, \underline{41}]$. In both $y$ and $z$-axes, Ewas a more reliable indicator of scaffold strengthening than the UCS. Consistent trends for UCS were not evident in the yor z-axes for scaffolds ofany particle size at increased magnetic field strength due tovariable defects that can have a large impact during mechanical compression.

Previous work demonstrated enhancement of $E$ and UCS due to lamellar wall alignment along the $y$-axis for a slurry mixture of $\mathrm{TiO}_{2}$ mixed with ferromagnetic $\mathrm{Fe}_{3} \mathrm{O}_{4}(\approx 50 \mathrm{~nm})$ at an applied magnetic field of $120 \mathrm{mT}$ [47]. Similar improvement in the $\mathrm{y}$-axis was evident for $\mathrm{ZrO}_{2}$ and $\mathrm{Fe}_{3} \mathrm{O}_{4}$ at $90 \mathrm{mT}$, although mineral bridges were aligned rather than the lamellar walls [49]. The amount of magnetic material added to those $\mathrm{TiO}_{2}$ and $\mathrm{ZrO}_{2}$ slurries (up to $9 \mathrm{wt}$.\% $\mathrm{Fe}_{3} \mathrm{O}_{4}$ particles) may have contributed to enhanced UCS values in the $y$-axis, which may help explain why similar trends were not observed in this work. The surface magnetized $\mathrm{Al}_{2} \mathrm{O}_{3}$ particles used in this work underwent chaining that led to observable lamellar wall alignment in the scaffold center at $75 \mathrm{mTfor} 350 \mathrm{~nm}$ scaffolds and $150 \mathrm{mT}$ for $225 \mathrm{~nm}$ scaffolds. The extent of particle chaining that occurred between magnetized particles dependedon particle size and thermodynamic variables(temperature, concentration)that affect aggregationand time evolution for chain formation before ice nucleation during freeze casting $[\underline{56}, \underline{57}, \underline{71}]$. Exploration of these three factors will continue with further magnetic freeze casting experimental work. 


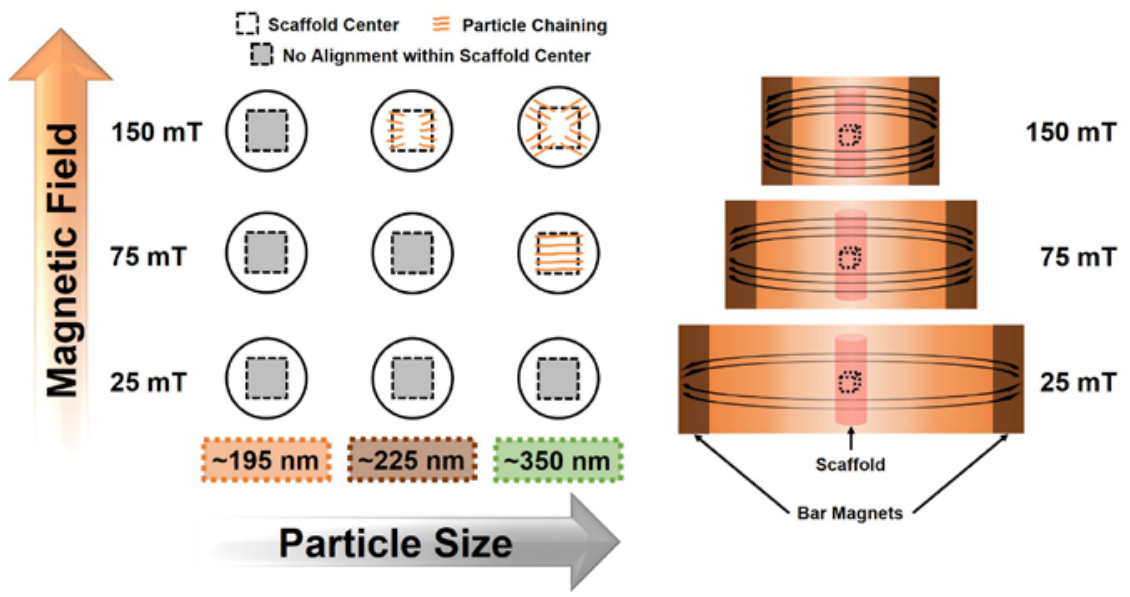

Figure 10. Lamellar wall alignment within the scaffold center as a function of magnetic field strength and magnetized particle size. The schematic indicates the extent of particle chaining (orange line) leading to lamellar wall alignment in the scaffold center (dotted box) for each magnetized alumina particle size at varying magnetic field strength. Lower magnetic field strength produced no lamellar wall alignment within the scaffold center for smaller particles (dotted gray box). A greater degree of particle chaining for larger particles led to more lamellar wall alignment, although a stronger magnetic field caused that alignment to be near the magnet poles instead of along the horizontal axis within the scaffold center.

The schematic diagrams in Figure 10summarize how particle chaining (orange lines) leads to lamellar wall alignment in the scaffold center (dotted box), or not (dotted gray box), for each magnetized particle size at varying magnetic field strengths. For the $225 \mathrm{~nm}$ particles, chaining initiated by greater magnetic field strength $(150 \mathrm{mT})$ overcame the thermal agitation force within the slurry, resulting in partially aligned lamellar walls within the scaffold center. For $350 \mathrm{~nm}$ particles with greater magnetic moment than $195 \mathrm{~nm}$ or $225 \mathrm{~nm}$ particles (Figure 6), more lamellar wall alignment occurred along the $y$-axis in the scaffold center at $75 \mathrm{mT}$, as compared to a magnetic field that was too strong (150 mT).

\section{CONCLUSIONS}

Freeze castingwas carried out for the first time with varying surface-magnetized alumina $\left(\mathrm{Al}_{2} \mathrm{O}_{3}\right)$ particle sizes $(195,225$ and $350 \mathrm{~nm}$ )andmagnetic fields $(0,75$ and $150 \mathrm{mT})$ applied perpendicular to the ice growth direction. This new method provides an avenue for examination of physical processes that affected particle magnetic chaining and lamellar wall alignment in sintered porous scaffolds. Conclusions obtained from this experimental work include:

- A mean number distribution for each particle typedetermined by the dynamic light scattering (DLS) technique, and applied in combination with magnetometer data for each magnetized particle 
size,indicated magnetic moment was higher for larger magnetized particles. Particle chaining, estimated from themagnetic coupling parameter $\lceil>1$, led to lamellar wall alignment in the scaffolds.

- Pore area and lamellar wall thickness values increased with increasing particle size. Increasing themagnetic field strength slightly increased lamellar wall thicknessfor only the largest particles (350 $\mathrm{nm}$ ), which had the largest magnetic moment and were most susceptible to particle chaining.

- Scanning electron microscopy characterization of the sintered scaffold center indicated the highest lamellar wall alignment for $350 \mathrm{~nm}$ particles at $75 \mathrm{mT}$, even though only $\approx 20 \%$ of the larger particles had $\Gamma>1$.An increase in the compressive Young's modulus $(\approx 100 \%)$ and strength $(\approx 20 \%)$ in the magnetic field direction was found over scaffolds prepared without an applied magnetic field.

- Both the particle size and magnetic field strength need to be judiciously selectedto optimize the mechanical properties. Larger particles produce more alignment and thicker lamellar walls thereby increasing the Young's modulus and strength. Even with the weak magnetic fields used in this study, the highest field produced non-parallel flux lines during freezing, resulting in angled lamellar walls that decreased the mechanical properties.

- Previous work on magnetic freeze casting used a heterogeneous slurry of magnetite particles mixed with oxide ceramic particles to align lamellar walls and mineral bridges. This work extends functionality of the process to include any materials that are surface magnetized.

\section{ACKNOWLEDGEMENTS}

This work is supported by a Multi-University Research Initiative (MURI) through the Air Force Office of Scientific Research of the United States (AFOSR-FA9550-15-1-0009) and a National Science Foundation Biomaterials Program Grant 1507169. The authors wish to acknowledge students who assisted with magnetic freeze casting and mechanical testing at University of California, San Diego (Christopher Yu, Ming Chengmingjtt, Alejandro Valdivia, Angelica Esparza). We thank Prof. Eric Fullerton, Prof. VitaliyLomakin and Sohini Manna (University of California, San Diego) for insightful discussions on magnetic properties, Prof. Marc A. Meyers (University of California, San Diego) for assistance with mechanical characterization, Ryan Anderson (University of California, San Diego) for SEM micrographs of magnetized particles and Dr. Jordi Faraudo (Institut de Ciencia de Materials de Barcelona), Prof. Albert P. Philipse and Ping Liu (Utrecht University, The Netherlands) for explaining fundamental details about the magnetic coupling parameter equation. 


\section{REFERENCES}

1. Kirschvink JL, Gould JL, "Biogenic magnetite as a basis for magnetic-field detection in animals," Biosystems, 13(3), 181-201 (1981).

2. Kalmijn AJ, Gonzalez IF, McClune MC, "The physical nature of life," Journal of PhysiologyParis,96(5-6), 355-362 (2002).

3. Walcott C, Green RP, "Orientation of homing pigeons altered by a change in direction of an applied magnetic-field," Science,184(4133), 180-182 (1974).

4. Gould JL, Kirschvink JL, Deffeyes KS, "Bees have magnetic remanence," Science, 201(4360), 10261028 (1978).

5. Kirschvink JL, Kobayashikirschvink A, Woodford BJ, "Magnetite biomineralization in the human brain," Proceedings of the National Academy of Sciences of the United States of America,89(16), 7683-7687 (1992).

6. $\quad$ Blakemore R, "Magnetotactic bacteria," Science,190(4212), 377-379 (1975).

7. Inoue K, Sassa K, Yokogawa Y, Sakka Y, Okido M, Asai S, "Control of crystal orientation of hydroxyapatite by imposition of a high magnetic field," Materials Transactions,44(6), 1133-1137 (2003).

8. Lee SH, Feng L, Yin J, Lee JS, Zhu X, Suzuki TS, Sakka Y, Tanaka H, "Dense SiC containing strongly aligned plate-like grains by magnetic treatment," Ceramics International,41(3), 5079-5084 (2015).

9. Ozen M, Mertens M, Snijkers F, Van Tendeloo G, Cool P, "Texturing of hydrothermally synthesized $\mathrm{BaTiO}_{3}$ in a strong magnetic field by slip casting," Ceramics International,42(4), 5382-5390 (2016).

10. Sakka Y, Suzuki TS, "Textured development of feeble magnetic ceramics by colloidal processing under high magnetic field," Journal of the Ceramic Society of Japan,113(1313), 26-36 (2005).

11. Suzuki TS, Sakka Y, "Fabrication of textured titania by slip casting in a high magnetic field followed by heating," Japanese Journal of Applied Physics Part 2-Letters,41(11A), L1272-L1274 (2002).

12. Suzuki TS, Sakka Y, "Control of texture in $\mathrm{ZnO}$ by slip casting in a strong magnetic field and heating," Chemistry Letters, 31(12), 1204-1205 (2002).

13. Suzuki TS, Uchikoshi T, Sakka Y, "Control of texture in alumina by colloidal processing in a strong magnetic field," Science and Technology of Advanced Materials, 7(4), 356-364 (2006).

14. Vriami D, Beaugnon E, Erauw JP, Vleugels J, Van der Biest O, "Texturing of 3Y-TZP zirconia by slip casting in a high magnetic field of 17.4T," Journal of the European Ceramic Society,35(14), 39593967 (2015).

15. Yang ZG, Yu JB, Li CJ, Zhong YB, Xuan WD, Ren ZM, Wang QL, Dai YM, Wang H, "Preparation of textured porous $\mathrm{Al}_{2} \mathrm{O}_{3}$ ceramics by slip casting in a strong magnetic field and its mechanical properties," Crystal Research and Technology,50(8), 645-653 (2015).

16. Le Ferrand H, Bouville F, Niebel TP, Studart AR, "Magnetically assisted slip casting of bioinspired heterogeneous composites," Nature Materials,14(11), 1172-+ (2015).

17. Erb RM, Libanori R, Rothfuchs N, Studart AR, "Composites reinforced in three dimensions by using low magnetic fields," Science,335(6065), 199-204 (2012).

18. Erb RM, Cherenack KH, Stahel RE, Libanori R, Kinkeldei T, Munzenrieder N, Troster G, Studart AR, "Locally reinforced polymer-based composites for elastic electronics," ACS Applied Materials \& Interfaces, 4(6), 2860-2864 (2012).

19. Libanori R, Erb RM, Studart AR, "Mechanics of platelet-reinforced composites assembled using mechanical and magnetic stimuli," ACS Applied Materials \& Interfaces,5(21), 10794-10805 (2013). 
20. Carnelli D, Libanori R, Feichtenschlager B, Nicoleau L, Albrecht G, Studart AR, "Cement-based composites reinforced with localized and magnetically oriented $\mathrm{Al}_{2} \mathrm{O}_{3}$ microplatelets," Cement and Concrete Research,78, 245-251 (2015).

21. Erb RM, Sander JS, Grisch R, Studart AR, "Self-shaping composites with programmable bioinspired microstructures," Nature Communications, 4, 1712 (2013).

22. Libanori R, Reusch FB, Erb RM, Studart AR, "Ultrahigh magnetically responsive microplatelets with tunable fluorescence emission," Langmuir,29(47), 14674-14680 (2013).

23. Kokkinis D, Schaffner M, Studart AR, "Multimaterial magnetically assisted 3D printing of composite materials," Nature Communications, 6, 10 (2015).

24. Martin JJ, Fiore BE, Erb RM, "Designing bioinspired composite reinforcement architectures via 3D magnetic printing," Nature Communications, 6, 7 (2015).

25. Wegst UGK, Bai H, Saiz E, Tomsia AP, Ritchie RO, "Bioinspired structural materials," Nature Materials, 14(1), 23-36 (2015).

26. Weiner S, Wagner HD, "The material bone: Structure mechanical function relations," Annual Review of Materials Science, 28, 271-298 (1998).

27. Launey ME, Buehler MJ, Ritchie RO, On the mechanistic origins of toughness in bone, in: Clarke DR, Ruhle M, Zok F (Eds.), Annual Review of Materials Research, Vol 40, Annual Reviews, Palo Alto, 2010, pp. 25-53.

28. Pidaparti RMV, Turner $\mathrm{CH}$, "Cancellous bone architecture: Advantages of nonorthogonal trabecular alignment under multidirectional joint loading," Journal of Biomechanics,30(9), 979983 (1997).

29. Zhang HF, Hussain I, Brust M, Butler MF, Rannard SP, Cooper Al, "Aligned two- and threedimensional structures by directional freezing of polymers and nanoparticles," Nature Materials,4(10), 787-793 (2005).

30. Deville S, Saiz E, Nalla RK, Tomsia AP, "Freezing as a path to build complex composites," Science, 311(5760), 515-518 (2006).

31. Munch E, Launey ME, Alsem DH, Saiz E, Tomsia AP, Ritchie RO, "Tough, bio-Inspired hybrid materials," Science,322(5907), 1516-1520 (2008).

32. Wegst UG, Schecter M, Donius AE, Hunger PM, "Biomaterials by freeze casting," Philosophical Transactions of the Royal Society A,368(1917), 2099-2121 (2010).

33. Hunger PM, Donius AE, Wegst UG, "Platelets self-assemble into porous nacre during freeze casting," Journal of the Mechanical Behavior of Biomedical Materials,19, 87-93 (2013).

34. Hunger PM, Donius AE, Wegst UGK, "Structure-property-processing correlations in freeze-cast composite scaffolds," Acta Biomaterialia,9(5), 6338-6348 (2013).

35. Naleway SE, Fickas KC, Maker YN, Meyers MA, McKittrick J, "Reproducibility of $\mathrm{ZrO}_{2}$-based freeze casting for biomaterials," Materials Science \& Engineering C-Materials for Biological Applications, 61, 105-112 (2016).

36. Araki K, Halloran JW, "Porous ceramic bodies with interconnected pore channels by a novel freeze casting technique," Journal of the American Ceramic Society,88(5), 1108-1114 (2005).

37. Araki K, Halloran JW, "Room-temperature freeze casting for ceramics with nonaqueous sublimable vehicles in the naphthalene-camphor eutectic system," Journal of the American Ceramic Society, 87(11), 2014-2019 (2004).

38. Guo R, Wang C-A, Yang A, "Piezoelectric properties of the 1-3 type porous lead zirconate titanate ceramics," Journal of the American Ceramic Society,94(6), 1794-1799 (2011).

39. Munch E, Saiz E, Tomsia AP, Deville S, "Architectural control of freeze-cast ceramics through additives and templating," Journal of the American Ceramic Society,92(7), 1534-1539 (2009).

40. Porter MM, McKittrick J, Meyers MA, "Biomimetic materials by freeze casting," JOM,65(6), 720727 (2013). 
41. Porter MM, Imperio R, Wen M, Meyers MA, McKittrick J, "Bioinspired scaffolds with varying pore architectures and mechanical properties," Advanced Functional Materials, 24(14), 19781987 (2014).

42. Naleway SE, Yu CF, Porter MM, Sengupta A, lovine PM, Meyers MA, McKittrick J, "Bioinspired composites from freeze casting with clathrate hydrates," Materials \& Design,71, 62-67 (2015).

43. Bouville F, Portuguez E, Chang YF, Messing GL, Stevenson AJ, Maire E, Courtois L, Deville S, "Templated grain growth in macroporous materials," Journal of the American Ceramic Society,97(6), 1736-1742 (2014).

44. Bouville F, Maire E, Meille S, Van de Moortele B, Stevenson AJ, Deville S, "Strong, tough and stiff bioinspired ceramics from brittle constituents," Nature Materials,13(5), 508-514 (2014).

45. Bai H, Chen Y, Delattre B, Tomsia AP, Ritchie RO, "Bioinspired large-scale aligned porous materials assembled with dual temperature gradients," Science advances,1(11), e1500849 (2015).

46. Bai H, Walsh F, Gludovatz B, Delattre B, Huang CL, Chen Y, Tomsia AP, Ritchie RO, "Bioinspired hydroxyapatite/poly(methyl methacrylate) composite with a nacre-mimetic architecture by a bidirectional freezing method," Advanced Materials, 28(1), 50-+ (2016).

47. Porter MM, Yeh M, Strawson J, Goehring T, Lujan S, Siripasopsotorn P, Meyers MA, McKittrick J, "Magnetic freeze casting inspired by nature," Materials Science and Engineering A - Structural Materials Properties Microstructure and Processing,556, 741-750 (2012).

48. Porter MM, Meraz L, Calderon A, Choi HJ, Chouhan A, Wang L, Meyers MA, McKittrick J, "Torsional properties of helix-reinforced composites fabricated by magnetic freeze casting," Composite Structures,119, 174-184 (2015).

49. Porter MM, Niksiar P, McKittrick J, "Microstructural control of colloidal-based ceramics by directional solidification under weak magnetic fields," Journal of the American Ceramic Society,99(6), 1917-1926 (2016).

50. Lu AH, Salabas EL, Schuth F, "Magnetic nanoparticles: synthesis, protection, functionalization, and application," Angewandte Chemie-International Edition,46(8), 1222-1244 (2007).

51. Neurauter AA, Bonyhadi M, Lien E, Nokleby L, Ruud E, Camacho S, Aarvak T, Cell isolation and expansion using Dynabeads((R)), in: Kumar A, Galaev IY, Mattiasson B (Eds.), Cell Separation: Fundamentals, Analytical and Preparative Methods, Springer-Verlag Berlin, Berlin, 2007, pp. 4173.

52. McPhail MR, Sells JA, He Z, Chusei CC, "Charging nanowalls: Adjusting the carbon nanotube isoelectric point via surface functionalization," Journal of Physical Chemistry C,113, 14102-14109 (2009).

53. Brown GE, Henrich V, Casey W, Clark D, Eggleston C, Felmy A, Goodman DW, Grätzel M, Maciel G, McCarthy MI, Nealson KH, Sverjensky DA, Toney MF, Zachara JM, "Review: Metal oxide surfaces and their interactions with aqueous solutions and microbial organisms," Chemical Reviews, 99, 77-174 (1999).

54. Kosmulski $\mathrm{M}$, "pH-dependent surface charging and points of zero charge. IV. Update and new approach," Journal of Colloid and Interface Science,337(2), 439-448 (2009).

55. Philipse AP, Maas D, "Magnetic colloids from magnetotactic bacteria: Chain formation and colloidal stability," Langmuir,18(25), 9977-9984 (2002).

56. Andreu JS, Camacho J, Faraudo J, "Aggregation of superparamagnetic colloids in magnetic fields: the quest for the equilibrium state," Soft Matter,7(6), 2336-2339 (2011).

57. Faraudo J, Andreu JS, Camacho J, "Understanding diluted dispersions of superparamagnetic particles under strong magnetic fields: a review of concepts, theory and simulations," Soft Matter,9(29), 6654-6664 (2013). 
58. Liu P, de Folter JWJ, Petukhov AV, Philipse AP, "Reconfigurable assembly of superparamagnetic colloids confined in thermo-reversible microtubes," Soft Matter,11(31), 6201-6211 (2015).

59. Evans DF, Wennerström H, The Colloidal Domain: Where Physics, Chemistry, Biology, and Technology Meet, 2nd ed., Wiley-VCH, New York, 1999.

60. Faraudo J, Camacho J, "Cooperative magnetophoresis of superparamagnetic colloids: theoretical aspects," Colloid and Polymer Science, 288(2), 207-215 (2010).

61. Martinez-Pedrero F, Tirado-Miranda M, Schmitt A, Callejas-Fernandez J, "Primary and secondary bonds in field Induced aggregation of electric double layered magnetic particles," Langmuir,25(12), 6658-6664 (2009).

62. Taboada E, Solanas R, Rodriguez E, Weissleder R, Roig A, "Supercritical-fluid-assisted one-pot synthesis of biocompatible core $\left(\mathrm{Y}-\mathrm{Fe}_{2} \mathrm{O}_{3}\right) / \mathrm{Shell}\left(\mathrm{SiO}_{2}\right)$ nanoparticles as high relaxivity $\mathrm{T}$-2-contrast agents for magnetic resonance imaging," Advanced Functional Materials, 19(14), 2319-2324 (2009).

63. Studart AR, "Biologically inspired dynamic material systems," Angewandte Chemie-International Edition, 54(11), 3400-3416 (2015).

64. Graeve OA, Madadi A, Kanakala R, Sinha K, "Analysis of particle and crystallite size in tungsten nanopowder synthesis," Metallurgical and Materials Transactions A,41(10), 2691-2697 (2010).

65. Graeve OA, Fathi H, Kelly JP, Saterlie MS, Sinha K, Rojas-George G, Kanakala R, Brown DR, Lopez EA, "Reverse micelle synthesis of oxide nanopowders: Mechanisms of precipitate formation and agglomeration effects," Journal of Colloid \& Interface Science,407, 302-309 (2013).

66. Vargas-Consuelos $\mathrm{Cl}$, Seo K, Camacho-Lopez M, Graeve OA, "Correlation between particle size and Raman vibrations in $\mathrm{WO}_{3}$ powders," Journal of Physical Chemistry C,118(18), 531-9537 (2014).

67. Wang H, Chen QW, Sun LX, Qi HP, Yang X, Zhou S, Xiong J, "Magnetic-field-induced formation of one-dimensional magnetite nanochains," Langmuir,25(12), 7135-7139 (2009).

68. Fitzner M, Sosso GC, Cox SJ, Michaelides A, "The many faces of heterogeneous ice nucleation: interplay netween durface morphology and hydrophobicity," Journal of the American Chemical Society,137(42), 13658-13669 (2015).

69. Cox SJ, Kathmann SM, Slater B, Michaelides A, "Molecular simulations of heterogeneous ice nucleation. I. Controlling ice nucleation through surface hydrophilicity," Journal of Chemical Physics, 142(18), 5 (2015).

70. Deville S, Maire E, Lasalle A, Bogner A, Gauthier C, Leloup J, Guizard C, "Influence of particle size on ice nucleation and growth during the ice-templating process," Journal of the American Ceramic Society, 93(9), 2507-2510 (2010).

71. Faraudo J, Andreu JS, Calero C, Camacho J, "Predicting the self-assembly of superparamagnetic colloids under magnetic fields," Advanced Functional Materials, 26(22), 3837-3858 (2016). 